\title{
De cacho, canto, corrales, leco, sueltas, apero y garabato soguero. Patrimonio material e inmaterial: el mundo fragmentado de los cantos de trabajo de llano, en Colombia ${ }^{*}$
}

\author{
JHON EMERSON MORENO RIAÑO**
}

Recibido: 14 de junio de 2019 - Evaluado: 19 de noviembre de 2019 - Aceptado: 3 de diciembre de 2019

Citar como: Moreno Riaño, J. E. (2020). De cacho, canto, corrales, leco, sueltas, apero y garabato soguero. Patrimonio material e inmaterial: el mundo fragmentado de los cantos de trabajo de llano, en Colombia. Hallazgos, 17(33), 133-162. DoI: https://doi.org/10.15332/2422409X.520707

* Artículo de reflexión, producto del proyecto de investigación "Los cantos de trabajo de llano en la Serranía del Manacacías”, desarrollado durante 2016-2018. Ganador de la beca de investigación de los "Fondos concursables para la salvaguardia del patrimonio cultural inmaterial de América Latina” del Crespial. Recibió el apoyo del Proyecto SGI 2428, financiado por la Vicerrectoría de Investigaciones de la Universidad Pedagógica y Tecnológica de Colombia.

** Candidato a magíster en Patrimonio Cultural de la Universidad Pedagógica y Tecnológica de Colombia (UPTC), Tunja, Boyacá, y miembro del Grupo Interdisciplinario de Investigaciones Arqueológicas e Históricas de esta misma universidad.

Correo electrónico: jhon.moreno06@uptc.edu.co

ORCID: https://orcid.org/0000-0002-9317-0206 


\section{Resumen}

Con base en un trabajo de investigación etnográfica con trabajadores de llano (vaqueros) en fundos y posadas ganaderas, y la participación en el proceso de implementación del Plan Especial de Salvaguardia de Carácter Urgente (PEScu), de cantos de trabajo de llano, este artículo propone una reflexión alrededor de la problemática que ha implicado la fragmentación del mundo cultural de esta manifestación. La problemática está representada en la forma de pensar los cantos, las sonoridades o los objetos sonoros y los saberes como patrimonio cultural inmaterial, y los objetos, las herramientas y los lugares asociados como patrimonio cultural material. Mientras el PEscu habla de conocer, revitalizar y comunicar como estrategias de salvaguardia, su gestión local se ha limitado principalmente a su divulgación desde lo musical. Como resultado, lo material ha sido poco valorado en la implementación de la salvaguardia. Se concluye entonces que lo sonoro y lo material son pensados como mundos independientes desde las instituciones culturales y sus procesos de salvaguardia, y se proponen puntos en común para comprender integradamente lo que en la práctica pareciera no necesitar integración, para conformar un solo universo sociocultural.

Palabras clave: cantos de trabajo de llano, patrimonio cultural inmaterial, patrimonio cultural material, objeto sonoro, salvaguardia. 


\title{
About cacho, song, corrals, leco, sueltas, apero and garabato soguero. Tangible and intangible heritage: the fragmented world of the Llano Work Songs, in Colombia
}

\begin{abstract}
From an ethnographic research work with llano workers (cowboys) in cattle ranches and farms, and the implementation process of the Special Safeguarding Plan for Llano Work Songs (PESCU), this article proposes a reflection on the problems that have involved the fragmentation of the cultural world of this expression. The problems are represented in the way of thinking the songs, loudness, sound objects and knowledge as intangible cultural heritage, and the objects, tools and associated places as tangible cultural heritage. While the PEscu talks about knowing, revitalizing and communicating as safeguarding strategies, its local management has been limited mainly to the dissemination as a music practice. As a result, the tangible universe has been underrated in the implementation of the safeguard. It is concluded that the sound and the tangible, are thought as independent worlds by the cultural institutions and their safeguarding processes, and common points are proposed to comprehend integrally what in practice seems not to need integration, to form a single sociocultural universe.
\end{abstract}

Keywords: llano work songs, intangible cultural heritage, tangible cultural heritage, sound object, safeguarding.

\section{De cacho, canto, corrales, leco, suelas, apero e garabato soguero. Patrimônio material e imaterial: o mundo fragmentado dos cantos de trabalho de lhano, na Colômbia}

\section{Resumo}

Baseado em um trabalho de pesquisa etnográfica com trabalhadores de lhano (vaqueiros) em fundos e pousadas pecuárias e a participação no processo de implementação do Plano Especial de Salvaguada de Caráter Urgente (PESCU), de cantos de trabalho de lhano, este artigo propõe uma reflexão sobre a problemática que tem implicado a fragmentação do mundo cultural desta manifestação. A problemática está representada na forma de pensar os cantos, as sonoridades o os objetos sonoros e os saberes como patrimônio cultural imaterial e os objetos, as ferramentas e os lugares associados como patrimônio cultural material. Mientras el PEScu fala de conhecer, revitalizar e comunicar como estratégias de salvaguarda, sua gestão local tem se limitado principalmente a sua divulgação desde o âmbito musical. Como resultado, o material tem sido pouco valorado na implementação da salvaguarda. Conclui-se então que o sonoro e o material são pensados como mundos independentes desde as instituições culturais e seus processos de salvaguarda e propõem-se pontos em comum para compreender integradamente o que na prática parecesse não precisar integração, para conformar um só universo cultural.

Palavras-chave: cantos de trabalho do lhano, patrimônio cultural imaterial, patrimônio cultural material, objeto sonoro, salvaguarda. 
“[...] de la talla del gana’o le dan razón el corral, las trancas y los llaveros, del trajín y el personal lleva cuenta el caracol por peones y por vaqueros, el muñeco habla del potro, la tarja e' los orejanos, la soga e' los cachaleros, de los vecinos cercanos, de los vecinos cercanos el trillo de los senderos [...]”

CARLOS CÉSAR "CACHI" ORTEGÓn, canción "Yo no le vendo mi fundo"

\section{La fragmentación de un universo cultural como indicadora de una crisis}

La carne bovina fue la principal dieta de los conquistadores que se aventuraron en la búsqueda de El Dorado, y como tal provocó el inicio de la colonización de los territorios de la cuenca del río Orinoco (Rausch, 1994). La ganadería también se utilizó como estrategia de ocupación de territorios, especialmente durante los siglos XVI y XVII, y así se fue convirtiendo no solo en la principal actividad económica, sino también en el elemento determinante y definitivo en los procesos de apropiación, distribución de tierras y de poder político y económico en el Nuevo Reino de la Corona española (Arias Vanegas, 2004). La ganadería también determinó y dio origen de manera predominante a las manifestaciones culturales de los llanos (Romero y Romero, 1989), como su música y sus temáticas asociadas al trabajo de llano, a los cantos, la oralidad, el coleo, el jaripeo, la gastronomía, los juegos y los conocimientos de la naturaleza y el universo en relación con los cuidados del ganado, tanto del lado de Venezuela como del de Colombia.

Características importantes de la ganadería de la región, como el manejo extensivo y los trabajos de llano en torno a vacadas, ya eran comunes a finales del siglo Xvi en los llanos orientales (Pinzón Martínez, 1991), mucho antes de que la Corona española permitiera las reducciones jesuitas a la Compañía de Jesús en algunos territorios de Arauca y Casanare. Sin embargo, en la historia común de estos pueblos, muchos de los portadores, según la información obtenida, tienden a pensar que los trabajos de llano fueron herencia exclusiva de los colonizadores jesuitas. "El llano nació aquí, en Arauca, en el hato Caribabare”; afirmaciones como esta se pueden extraer de relatos orales, entre otros relacionados con las leyendas del tesoro jesuita de Caribabare, por parte de antiguos trabajadores de llano. También conforman cierto imaginario que les concede la legitimidad y el orgullo de la llaneridad a algunos vaqueros de este departamento, que así se lo atribuyen. Esto sin desconocer que, según las crónicas, la Compañía de Jesús 
también llegó a otros territorios llevando la religión y enseñando a los indígenas y a las poblaciones afro las técnicas y los secretos de la ganadería y el modelo de hato (Rausch, 1994). Tal modelo fue lentamente implementado hacia finales del siglo xvir, para iniciar una gran revolución económica basada en la explotación de la ganadería extensiva.

Con el tiempo, este modelo de producción pecuaria fue generando diversas prácticas, representadas en un acervo cultural desarrollado a partir de la oralidad de sus pobladores — criollos, indígenas y afro— que por siglos ha trascendido lo material y lo técnico de la cría del ganado vacuno y equino. Este universo forma parte del capital cultural de los departamentos de la Orinoquia donde se han desarrollado, como una de sus principales prácticas, los cantos de trabajo de llano, junto con todo el tejido material e intangible que compone ese universo relacionado con el trabajo de llano. El componente achagua en esta cultura es muy significativo. Por tanto, no es extraño que de manera similar al mundo indígena, donde "todo está interrelacionado: el pensamiento, la identidad, el alimento, la palabra, la acción, la relación con uno mismo, con los otros, con la tierra, con los animales, con los ancestros, con lo divino" (Caicedo Terán y Espinel, 2018, p. 28), también en la cultura llanera tradicional el mundo cultural esté interrelacionado y articulado, comprendiendo por siglos lo material y lo inmaterial como una unidad. De ahí la importancia de evitar su fragmentación.

Esta cultura asociada a la ganadería se les reconoce a las comunidades que han poblado los territorios aledaños al río Orinoco y todos sus afluentes, tanto del lado venezolano como del colombiano, desde el periodo hispánico. Se caracteriza por una marcada inclinación socioeconómica a la cría de ganados bovinos, tanto que

[...] culturalmente se considera que la ganadería ha sido el fundamento del origen y desarrollo de un grupo regional particular: los llaneros. De esta forma, la vida económica y cultural de la región ha sido reducida a todo aquello que provenga o esté relacionado con la ganadería. (Arias Vanegas, 2004, p. 4)

Con base en esta actividad no solo se han desarrollado los cantos de trabajo de llano como herramientas de domesticación y comunicación, sino que también ha surgido todo un universo material (Reyes, 2003) representado en saberes para la fabricación de objetos y sus usos, además de la adecuación de espacios para las necesidades que la cría de ganado y los requerimientos en la adaptación a la precariedad del entorno han demandado desde el siglo XVII (Pérez Radziunas, 2014). Por tanto, este universo cultural, comprendido tanto desde lo material como desde lo inmaterial, siempre ha estado articulado e integrado a este grupo humano, al contexto ganadero y a su cultura pastoril. 
Antes de abordar los cantos de trabajo de llano es necesario aclarar que la reseña hecha sobre el trabajo de llano busca una aproximación a la actividad que esta denominación representa en cuanto a su origen, a la sociedad que la ha practicado, al territorio donde se ha dado, al mundo material involucrado y, al menos en un fugaz recorrido, al aspecto histórico que permite ubicarnos temporalmente desde la reflexión que interesa a este artículo. Este texto, además, se ha concebido con los aportes de la reflexión sobre el trabajo de campo que lo motiva y la experiencia en la coordinación local de estrategias de salvaguardia, en diferentes lugares, durante 2014 y 2015, con un grupo de treinta portadores ${ }^{1}$ de cantos de trabajo de llano (vaqueros) de los departamentos de Casanare, Meta, Vichada y Arauca, en el marco de la implementación del Plan Especial de Salvaguardia de Carácter Urgente (PEScu) de los cantos de trabajo de llano (cantos, en adelante). Este trabajo de implementación buscó en su momento articular y contextualizar la manifestación con su universo cultural; sin embargo, no llegó a impactar más allá de lo local, por tratarse de un territorio extenso. Este texto también fue concebido sobre la base de experiencias posteriores (2016 a 2018), en la implementación de estrategias de salvaguardia de impacto local y en la ejecución de una beca de investigación sobre caminos y posadas ganaderas, en cuanto escenarios de práctica y transmisión de esta manifestación, en la Serranía del Manacacías, Meta, otorgada por el Crespial al autor.

En 2014, mediante la Resolución 054, el Ministerio de Cultura incluyó los cantos en la Lista Representativa de Patrimonio Cultural Inmaterial (LRPCI), y de acuerdo con la legislación de patrimonio cultural establecida en las leyes 397 de 1997 y 1185 de 2008, que se reglamentan mediante el Decreto 2941 de 2009, se aprobó un Plan Especial de Salvaguardia que determinó su carácter urgente. Esto se aprobó porque a través del trabajo de identificación, caracterización y diagnóstico iniciado en 2011, se estableció que sus depositarios o portadores son de edad avanzada, lo cual dificulta la transmisión de la práctica, además de que su territorio enfrenta graves amenazas internas y externas relacionadas principalmente con la violencia y los procesos de globalización. Por estas razones, que hacen del trabajo de llano asociado a la ganadería extensiva una actividad agonizante y por el poder simbólico y representativo que tiene el canto de trabajo de llano para sus portadores y comunidades, se determinó la inclusión del canto y no del trabajo de llano en la LRPCI. Estos cantos son "el testimonio de los conocimientos

1 En este contexto un portador o una portadora es toda persona que practica los cantos de trabajo de llano y que tiene el reconocimiento de su comunidad como actor importante en la transmisión de estas prácticas y saberes. 
centenarios que aún hoy pueblan la memoria de los habitantes de los departamentos de Casanare, Arauca, Meta y Vichada” (Ministerio de Cultura, 2013, p. 5).

Sin embargo, una de las principales problemáticas de la salvaguardia de los cantos de trabajo de llano está representada por el direccionamiento que se ha dado desde las instituciones locales a la implementación de su PESCU, a partir de las estrategias de divulgación exclusiva del canto. Esto ha satisfecho el imaginario territorial creado de la manifestación, incluso desde la misma música llanera a través de las grabaciones y el discurso del folclor, y ha llevado las tres estrategias propuestas en el documento del Plan — conocer, revitalizar y comunicar- exclusivamente al plano de los escenarios y a lo que pareciera ser la creación de una marca cultural hegemónica asociada al joropo y los festivales. Tal marca, por ser popular, no necesariamente es beneficiosa para la comunidad de portadores y para la diversidad de prácticas y saberes que componen la cultura llanera, porque establece relaciones de verticalidad en la interconexión con que se relacionan los elementos formantes del contexto en que se dan estos cantos.

Para acercarnos a este proceso de patrimonialización, debemos hablar entonces de una intervención de la construcción social de los territorios, a través de una determinación de lo patrimonializable y lo que no es sensible de serlo, porque al fin de cuentas son las instituciones, empezando por la Unesco, las que determinan esto. Hablamos, entonces, a escala global, de una restricción y un acotamiento que contribuyen en la "reproducción de una cartografía de poder, en la que ciertos continentes, países y grupos son relegados a expresiones subvaloradas en el ámbito del patrimonio cultural” (Lacarrieu, 2008, p. 5), pero que hoy "la llamada globalización obliga a salvaguardar (manteniendo) las diferencias — culturales - en aras del mercado” (Santamarina Campos, 2013, p. 265), en este caso, el mercado del espectáculo musical.

"La institución del PCI puede entonces probar (según una perspectiva esencialista) o producir (según una perspectiva constructivista) un vínculo comunitario por el hecho de que una práctica cultural otorgue a un grupo un 'sentimiento de identidad y de continuidad'” (Bortolotto, 2014, p. 14). Esto puede ser percibido cuando tenemos un grupo de vaqueros que han vivido en un contexto de ruralidad, que difícilmente se han pensado como una comunidad debido a las dificultades o la carencia de medios de comunicación, pero que tocados por el ímpetu que infunde la patrimonialización y la reconstrucción de un pasado, son contagiados por una aspiración patrimonial. Tal hecho los lleva a establecer un grupo más o menos homogéneo y numeroso que podrá concretar nuevas comunidades alrededor de las prácticas a las que confieran una función identitaria federadora (Bortolotto, 2014). 


\section{Eros enfrenta a Tánatos}

Los cantos han sido incluidos en la LRPCI de la nación luego de un proceso de identificación, caracterización, documentación y evaluación de riesgos, realizado de la mano de diferentes entidades y portadores. Esta manifestación cultural, además, fue incluida en 2017 por la Unesco en la Lista de salvaguardia urgente del patrimonio cultural inmaterial de la humanidad (Unesco, 2017).

Los cantos de trabajo de llano se conocen en la institucionalidad, según el documento del PEScU, como un

[...] conjunto de expresiones inmateriales del entramado cultural de la Orinoquia colombo-venezolana, asociado a las actividades tradicionales de la ganadería extensiva que se desarrollan en la región desde el siglo xvir y con mayor auge durante los siglos XIX y xx. (Ministerio de Cultura, 2013, p. 11)

Si bien en la caracterización que se hace de la manifestación, en el PEScu se profundiza en aspectos como el territorio, los orígenes históricos de su práctica, sus depositarios o portadores, su función social y su importancia como herramienta de trabajo en las labores de domesticación, arreo, cuidado, ordeño, manejo y doma, conocidas como "trabajo de llano", así como en la relación hombre-animal. En este documento no se logra dimensionar el mundo cultural que se articula con el universo material del que forman parte los cantos, representado especialmente en los objetos, los saberes y las prácticas relacionados con la elaboración de estos y el papel que han cumplido como herramienta en las labores que son acompañadas con lecos, silbos, japeos, cantos de vela y tonadas de ordeño, sonoridades conocidas como "cantos de trabajo de llano".

Tampoco a los objetos se les da el reconocimiento suficiente como herramientas o elementos importantes para tener en cuenta en el momento de emprender un proceso de revitalización o resignificación de la manifestación, de forma que se puedan mitigar los riesgos de desaparición diagnosticados para emprender un proceso de salvaguardia integral.

El haber incluido los cantos en la LRPCI de la nación ha traído impactos y cambios acelerados, tanto en la manifestación como en los portadores y los territorios donde se practican. Así como en antropología las nociones de espacio se apoyan en conceptos de quiebre y ruptura para poder teorizar sobre conflictos socioculturales o culturas de frontera con base en conceptos como discontinuidad (Gupta y Ferguson, 2008), en los procesos de patrimonialización, con miras a lograr claridades 
conceptuales y teóricas y una práctica formulación e implementación de un plan de salvaguardia, en las instituciones se ha tendido a la fragmentación del universo cultural desde la misma concepción del patrimonio entre lo material y lo inmaterial. Uno de los impactos más notables ha sido el haber empezado a incluir los cantos en algunos planes municipales y departamentales de desarrollo, en departamentos como Meta, y más tímidamente en Casanare. Esto ha hecho que los cantos se conozcan a través de espectáculos masivos, y ha incentivado su valoración y práctica casi de forma exclusiva, desde el aspecto estético musical, pero se ha descontextualizado su práctica mediante la proliferación de concursos y festivales, lo que ha dejado de lado sus usos y la materialidad asociada al trabajo de llano y al contexto sociocultural en el cual surgieron (figura 1).

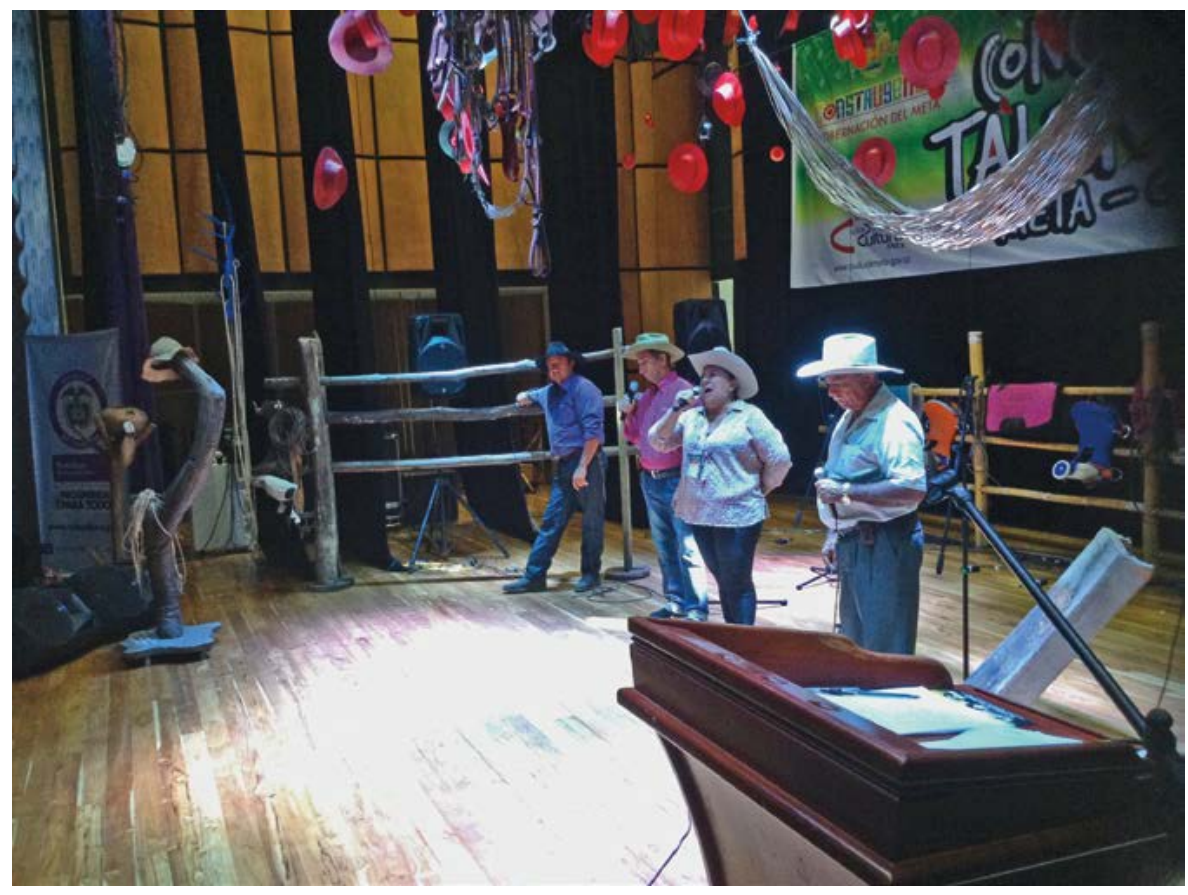

Figura 1. Concurso infantil “Pa' Lante Talento Llanero - Cantos de trabajo de llano, 2014”, en el departamento del Meta, Colombia Fuente: archivo personal del autor 
Esto se ha evidenciado por medio de relatos de los portadores, de la observación de los principales festivales de joropo de la Orinoquia y del cambio en la forma de transmisión intergeneracional de los cantos, que ha pasado de los corrales, fundos, hatos, caminos ganaderos y sabanas a las aulas de clase en academias de música y casas de la cultura. No se afirma de ningún modo que este trabajo pedagógico musical y de divulgación a través del espectáculo alrededor de esta manifestación esté mal. Por el contrario, ha permitido que muchas personas la conozcan. Pero, quizás, la salvaguardia y el valor de lo patrimonial que tienen estos cantos no debería ser reducida a un repertorio musical, que los despoja de sus formas de transmisión y de su universo cultural subyacente, incluso muchas veces prescindiendo de la comunidad de portadores.

En el contexto del patrimonio cultural donde el Estado interviene traduciendo "una manifestación compleja y relacional [como los cantos] a un sistema de naturaleza administrativa y segmentada, en últimas despoja a las personas de dicha manifestación que las hacía singulares y que generaba procesos de identidad" (Salge Ferro, 2018, p. 102). En este juego de poder que genera la inclusión de un elemento cultural como los cantos en la LRPCI, Eros debe enfrentar a Tánatos, siguiendo la idea de Salge Ferro (2018). Para esto, se vale del simulacro seductor del espectáculo con el objeto de vencer la pulsión de muerte o desaparición que siempre se presenta como una amenaza latente a las manifestaciones culturales, especialmente las que son practicadas en la ruralidad colombiana. "Para ello [Eros] no duda en espectacularizar los recursos culturales y proponer sus listas de maravillas como un objeto de deseo que debe ser alcanzado por esas manifestaciones que se traducen en patrimonio" (Salge Ferro, 2018, p. 102).

Entonces esta proliferación de espectáculos alrededor de los cantos no pareciera estar aportando algo positivo desde el mundo cultural integrado que subyace a ellos, pero sí ha generado un interés voyerista sobre la manifestación, "que se alimenta de las dinámicas del mercado y el turismo, y erotiza esa nación que el Estado rige, registra y domestica” (Salge Ferro, 2018, p. 102) con sus políticas y legislaciones patrimoniales. Tomemos como ejemplo la ruptura que se ejerce entre el universo material y el mundo intangible de prácticas y saberes que se encuentran en cada depositario o portador. Si bien, por un lado, se "refuncionalizan" los cantos y se abren posibilidades económicas desde el aspecto musical para intérpretes ${ }^{2}$ de estos nue-

2 No cabe ya el concepto de portador porque el canto de trabajo de llano pasa a ser parte del repertorio musical, quizás representando un género, quizás un estilo. Ahora quien lo canta será 
vos repertorios a través del fenómeno generalizado de tarimización municipal en los festivales de música llanera de los pueblos, por otro lado, se descontextualiza una práctica que, además de lo musical, representa, si no toda, sí gran parte de la historia cultural, política y económica de un complejo grupo social, tanto desde lo intangible como desde lo material.

En otro ámbito, esta espectacularización sí está cumpliendo una función importante en el contexto político e institucional, lo que ha generado fáciles réditos en cuanto a la dinamización superficial de la gestión cultural y política para gobernantes locales. En este orden de ideas, la instrumentalización política e institucional de esta manifestación debiera ser una de las principales categorías de análisis crítico que se debe seguir cuando se quiera hablar de la gestión institucional del patrimonio por parte de expertos en legislación y cultura. Estos réditos institucionales pueden ser percibidos por los públicos y argumentados fácilmente en la rendición de cuentas que hacen los programas de gobierno como logros positivos de la gestión patrimonial en la esfera política local. Pero en la realidad no pasan de ser el producto de una gestión perezosa y poco consensuada, que muestra un gran cubrimiento e impacto poblacional con la medición de indicadores sobre el papel, pero que no va más allá de eso. Esta finalidad, en últimas, pareciera ser la que se busca mostrar desde las instituciones locales, sin importar si va en detrimento de los intereses de los grupos sociales a los que pertenecen los portadores o depositarios de una manifestación cultural que viene siendo fragmentada, y cuyo universo cultural se ha ido desarticulando desde el mismo momento en que se incluyó en la lista de patrimonio cultural.

\section{La integralidad de un universo de objetos y algunas pistas para empezar a comprenderlos}

Alrededor de los cantos se asocian muchos contextos y espacios construidos como el corral, la majada, el pozuelo o tabique, la tasajera, la manga, el embudo, el paradero, el llavero, el mangón o el caney, entre otros (figuras 2, 3, 4 y 5); muchas prácticas y saberes relacionados con la fabricación y uso de estos espacios.

un intérprete, no ya un portador, en el sentido de ser un depositario de los saberes, técnicas y prácticas asociadas al acervo cultural y un contexto de trabajo de llano. 


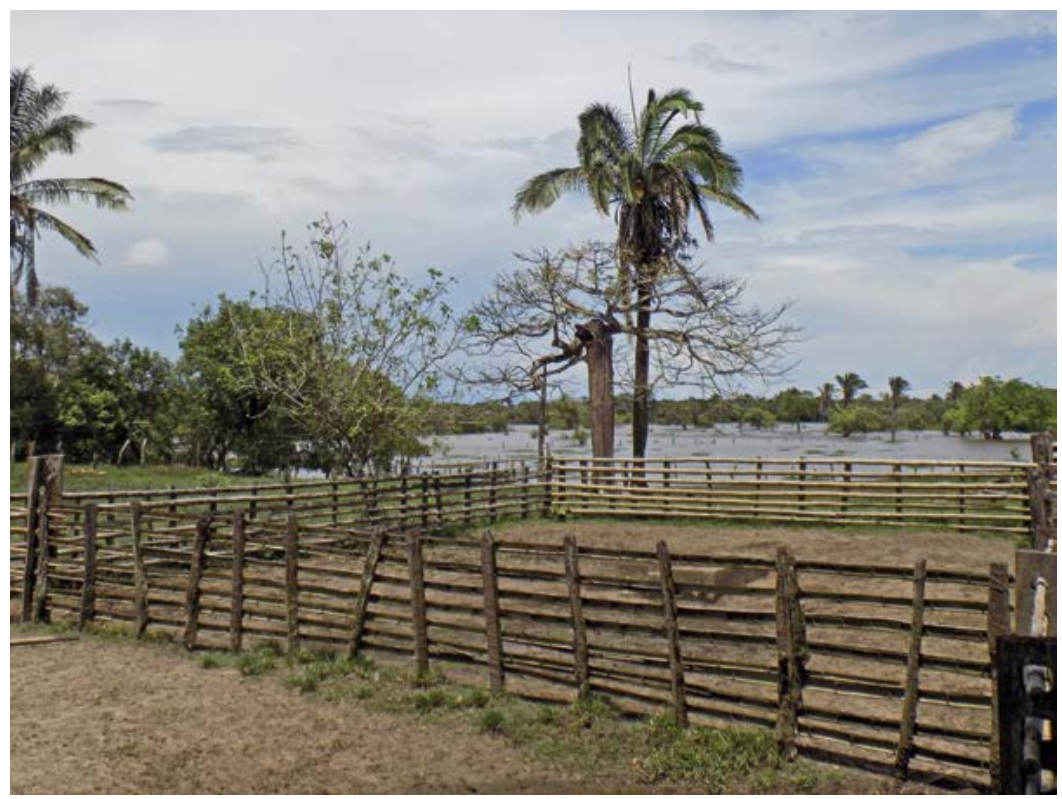

Figura 2. Corral de construcción tradicional en guafa o guadua Fuente: archivo personal del autor

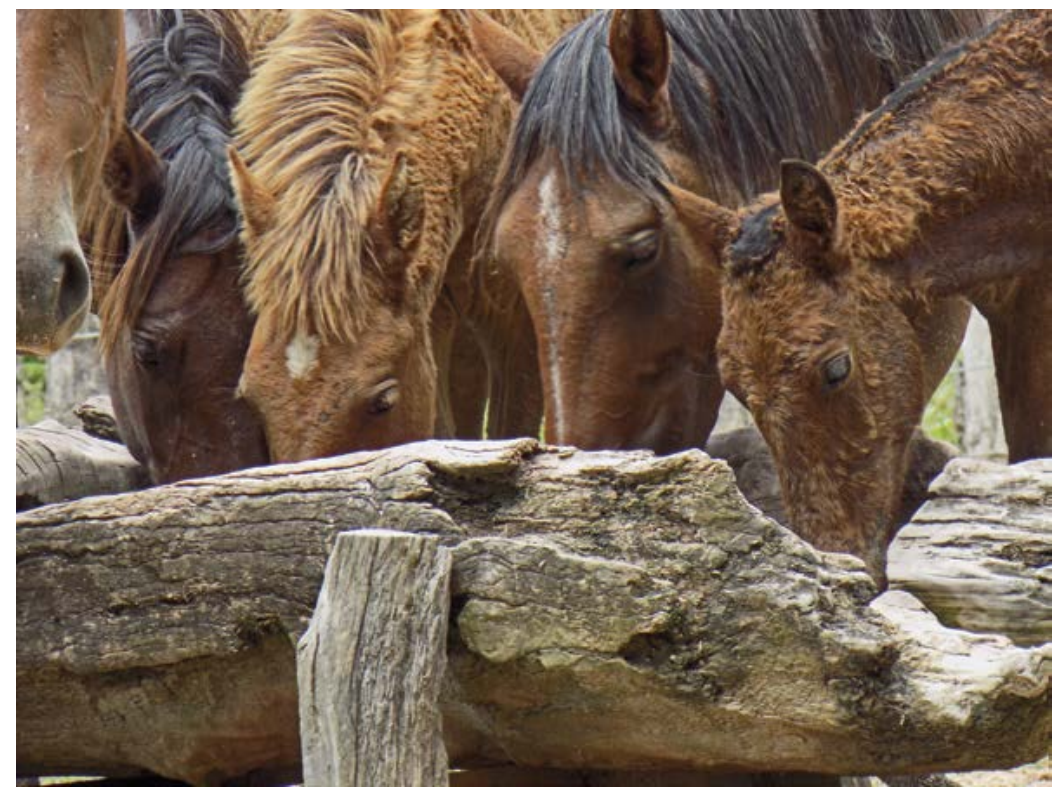

Figura 3. Pozuelo o tabique para dar sal, caña o melaza al ganado, a los cerdos o a los caballos Fuente: archivo personal del autor 
De cacho, canto, corrales, leco, sueltas, apero y garabato soguero...

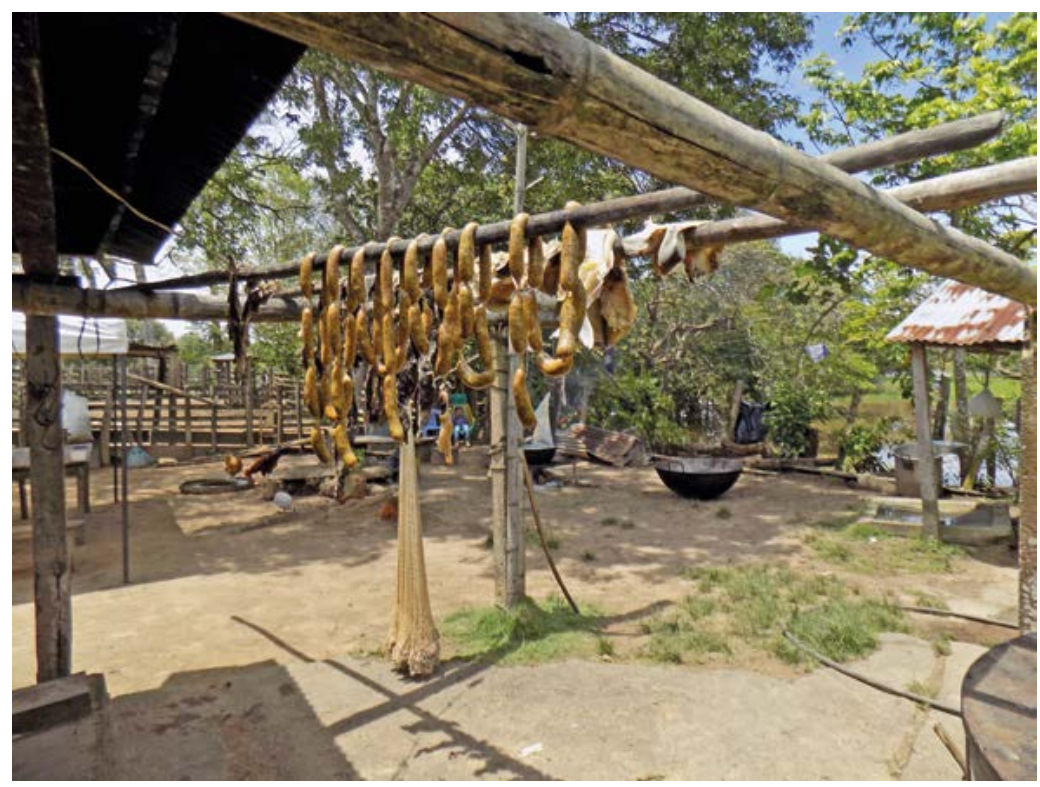

Figura 4. Tasajera usada para orear o secar los productos cárnicos de consumo interno Fuente: archivo personal del autor

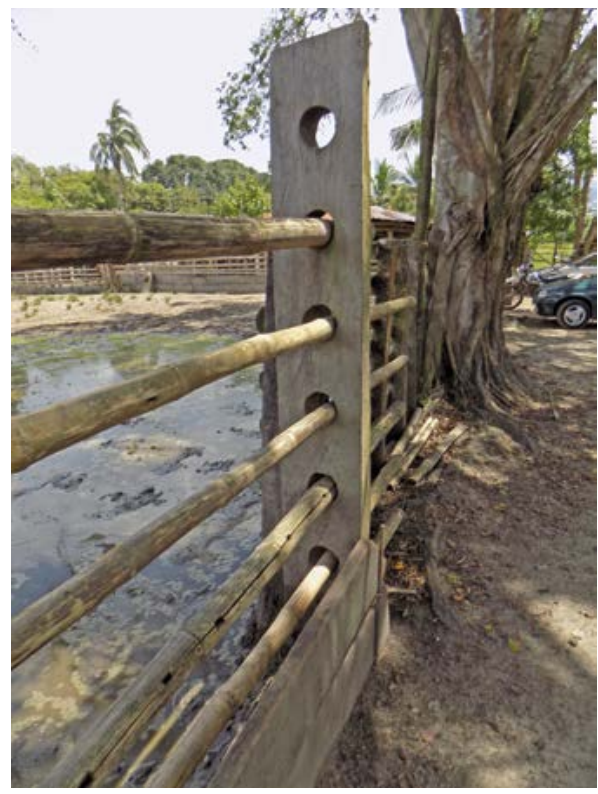

Figura 5. Llavero con sus trancas para cerrar entrada al corral Fuente: archivo personal del autor 
De otro lado, están los objetos como la totuma, la camaza, el burro, el sujeto, el botalón, el arción, el soguero, la suelta, el tapaojo, la falseta, la soga con su correspondiente arrebiate y cagalereo, así como los cachos acondicionados para llamar la canoa en los pasos de los ríos (figuras 6, 7 y 8), y muchos más artefactos asociados al mundo de la ganadería tradicional. Todo este conjunto de elementos, usos y espacios, y la relación que entre ellos se establece, más otros saberes comprendidos dentro la oralidad, como los relatos de espantos, los cuentos infantiles, los rezos medicinales y de maleficio, los cuentos de cacho, los saberes gastronómicos y los conocimientos sobre construcción de viviendas y medicina tradicional para humanos y animales, conforman el contexto de esta manifestación cultural. Este contexto no se articula con claridad a la manifestación, y no se le da la relevancia necesaria en el PEscu, de tal manera que permita activar procesos de implementación en pro de su necesaria integralidad, en lugar de tender a considerarlo más como un conjunto de manifestaciones en sí mismas, en las que los cantos vienen siendo comprendidos e interpretados por las instituciones culturales locales como un elemento independiente o desarticulado.

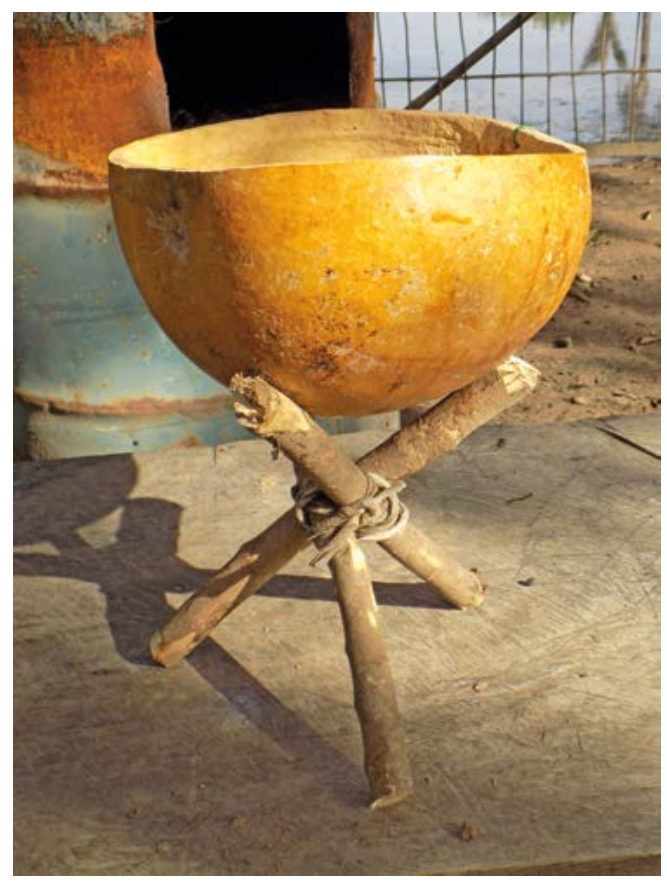

Figura 6. Camaza y burro para el ordeño Fuente: archivo personal del autor 
De cacho, canto, corrales, leco, sueltas, apero y garabato soguero...

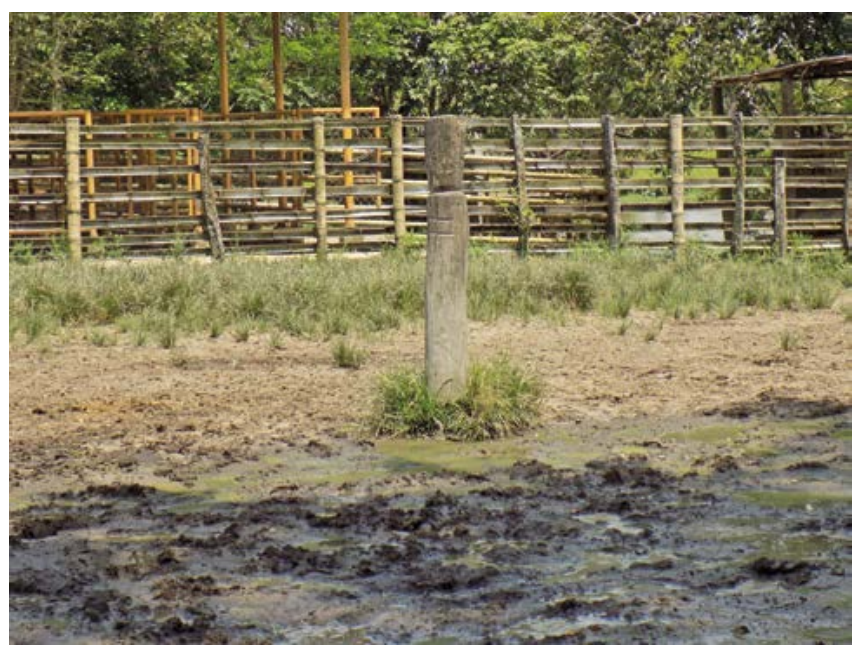

Figura 7. Botalón o muñeco ubicado en el centro del corral Fuente: archivo personal del autor
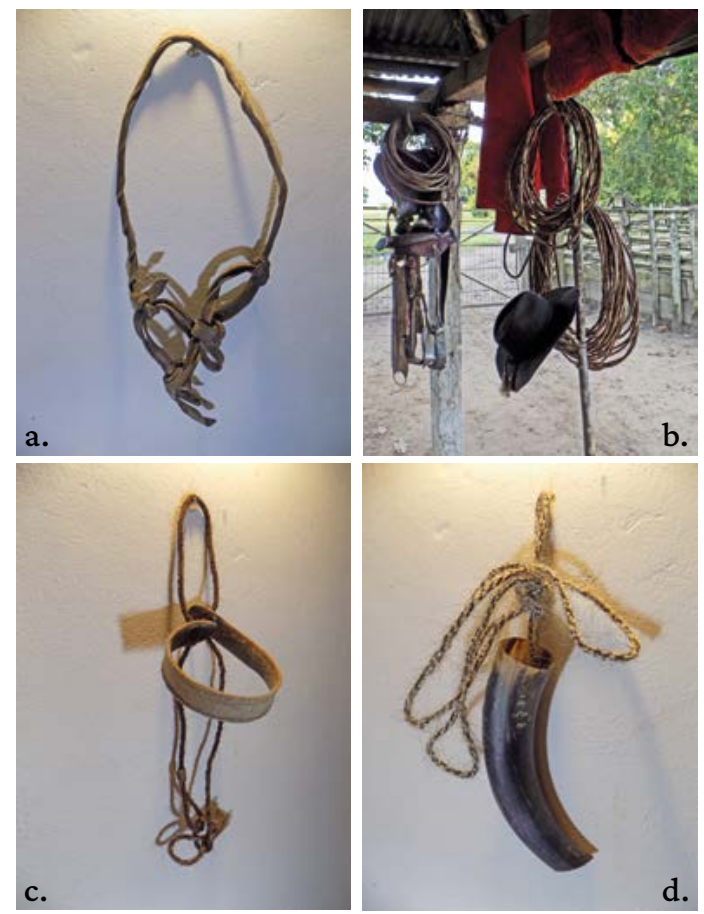

Figura 8. a) suelta, b) sogas en el garabato, c) tapaojo, d) cacho para llamar. Fuente: archivo personal del autor 
No es gratuito que se haya llevado a cabo el reconocimiento nacional de esta práctica como un patrimonio que debe encontrar su sentido al responder a "la identidad de un pueblo, de cuya historia y trayectoria cultural debe dar testimonio como algo vivo" (Noguera, 2002, p. 109), ya que, a través de la historia de hombres y mujeres de este territorio, el trabajo diario, la relación con el ganado y el conocimiento profundo de la naturaleza, les demandó la fabricación de ciertas herramientas y conocimientos técnicos sobre su elaboración. Así,

[...] aprendieron que el ganado, además de servirles de fuente de alimentación, poseía un cuero con el cual se podían hacer rejos, riendas, tapa-ojos, sueltas, bozales y campechanas; una grasa que servía para hacer jabones; unos cachos útiles para hacer recipientes; un sebo del cual se podían hacer velas. (Reyes, 2003, p. 34)

Además, en su entorno tuvieron que encontrar la solución a otras necesidades y desarrollaron conocimientos sobre otros animales y sobre las plantas. Aprendieron "que el caballo también tenía una crin con la que se podían hacer cabestros; y que en el monte y la sabana se encontraba el material que permitía hacer totumas, camazos, mandadores, curiaras, canaletes, garabatos y botalones, etc.” (Reyes, 2003, p. 34).

Remontémonos, a través de los relatos de los trabajadores de llano, a la época en que las sabanas de la Orinoquia eran comunes y, por tanto, no existían las cercas ni las divisiones territoriales. Luego de que los jesuitas fueron expulsados de la Orinoquia por parte de la Corona española, sus ganados se alzaron (se volvieron salvajes) a las sabanas, y la mayor parte de estas se convirtieron en cimarroneras o mañoseras (lotes de ganado salvaje). Entonces el pastoreo de estos ganados era una tarea peligrosa para los trabajadores de llano y requería técnicas y herramientas especializadas para evitar riesgos a los trabajadores y a los animales. Los dueños tenían su rodeo o grupo de rodeos, y en medio del pastoreo cotidiano era común que las cabezas de ganado se mezclaran accidentalmente; por tanto, se procedía, cada tanto, a la recogida de las puntas (lotes de reses) de ganado mezclado para realizar el aparte, la marca y el conteo de las reses (trabajos de llano), con lo cual se lograba determinar el tamaño del rodeo que le pertenecía a cada dueño.

Muchas veces, en estos apartes, había cabezas de ganado que no permitían ser arreadas y debían ser enlazadas con la soga. Ahora bien, una vez enlazado un vacuno, la pregunta es ¿cómo soltarlo luego en el sitio a donde se pretende llevar? Pero, sobre todo, ¿cómo soltarlo evitando, en lo posible, el maltrato del animal y el riesgo del vaquero? Se debe tener en cuenta que este ganado criollo y cimarrón es bravo, y por 
esta causa los relatos de los trabajadores de llano están plagados de historias de heridos y muertos, a causa de cornadas de los toros cimarrones o de caídas de caballos indomables en el fragor del trabajo de llano.

\section{Objetos materiales o sonoros, solución ante las demandas del contexto}

En busca de una solución a la problemática descrita anteriormente, y a otras para las cuales el contexto fue demandando soluciones, se fabricaron objetos como la cachera (figura 9). Al caracterizar algunas herramientas y objetos relacionados con el trabajo de llano, en compañía de un grupo de vaqueros, decidimos centrarnos en este objeto por su especial significado para el trabajo de llano y por ser el símbolo de un llano que tiende a desaparecer. La cachera da solución a una necesidad asociada al manejo cotidiano del ganado cuando se precisaba soltar un animal después de haber sido enlazado, evitando así el maltrato animal y cualquier peligro para el vaquero. La función básica de este objeto se relaciona con la acción de soltar un vacuno.

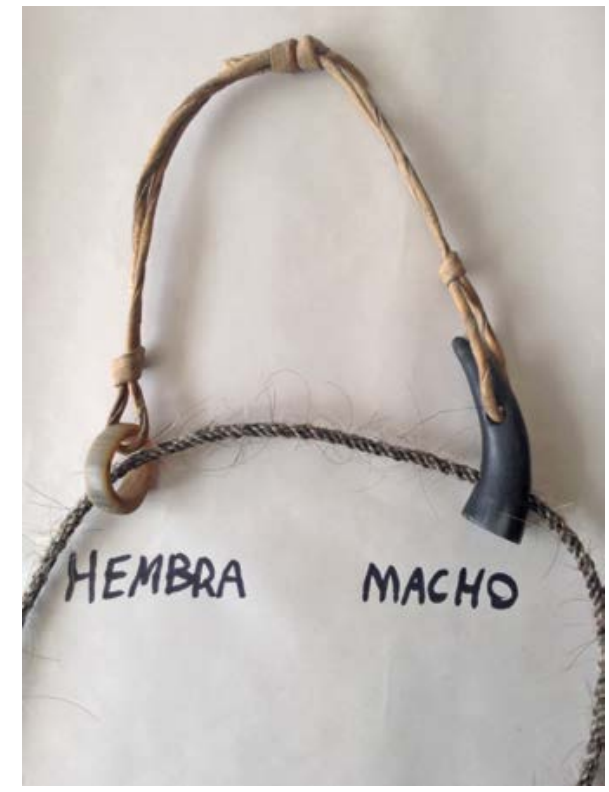

Figura 9. Cachera

Fuente: archivo personal del autor 
Existe una dimensión estructural de los objetos que "nos permite conocer qué es el objeto a partir de comprender ¿cómo? y ¿con qué? está elaborado” (Sanín, 2016, p. 32). Esta dimensión, entre otras cosas, se refiere también al contexto de producción, a partir de aspectos como la disponibilidad de materiales para la construcción del objeto, las necesidades de uso que demandan cierto diseño y resistencia y el proceso mismo de construcción, que desde el análisis da luces sobre el nivel de desarrollo de la sociedad que lo produjo, en cuanto a si hubo o no intervención de algún tipo de tecnología o de maquinaria en su elaboración. Se debe tener en cuenta, entonces, que la cachera debe soportar el peso y la fuerza de un toro, que usualmente oscila entre los 450 y los 600 kilos en promedio, en el caso de las razas criollas. Para esto, el material esencial con que se contaba era la piel de los mismos vacunos, que fue usado para fabricar las sogas y las marotas ${ }^{3}$ según el nivel de dureza requerido (figura 10), y en este caso también junto con los cuernos de los vacunos para fabricar la cachera. Para el diseño del mecanismo se dispuso que estuviera compuesto de una hembra — argolla construida de cacho de res-instalada en uno de los extremos del trozo de rejo — usualmente doble para mayor resistencia - de unos 60 centímetros de extensión, que rodea el cuello del animal, y un macho, también de cacho - la punta del cuerno de una res- perforado, de manera que permita el paso de la soga de forma justa, a través del orificio (figura 9).

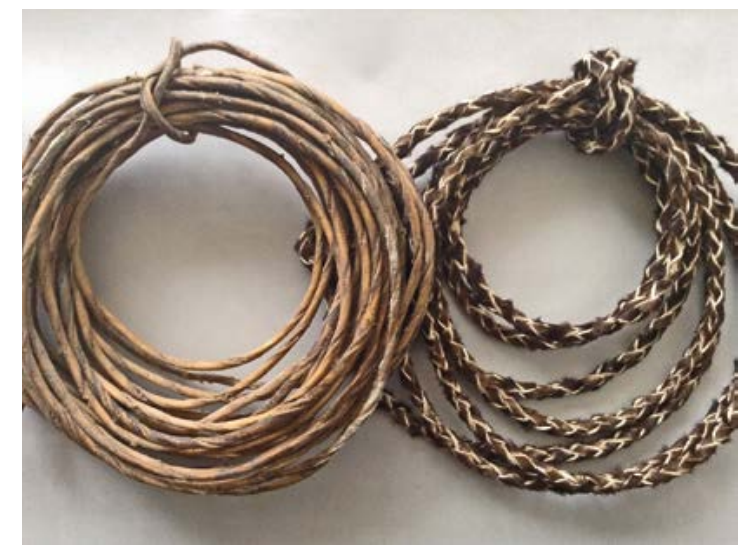

Figura 10. Soga con técnica de torcido y marota con técnica de tejido Fuente: archivo personal del autor

3 Soga y marota son dos objetos que difieren en su proceso y técnica de construcción. Ambos sirven para enlazar, pero la segunda es más fuerte que la primera. La técnica de la soga es una correa de cuero torcido; la marota se fabrica con una técnica de tejido, y para ello se requieren mínimo cuatro correas angostas (cuatro órdenes); según el requerimiento de dureza, se fabrican de seis y ocho órdenes, para el manejo de toros muy grandes o peligrosos. 

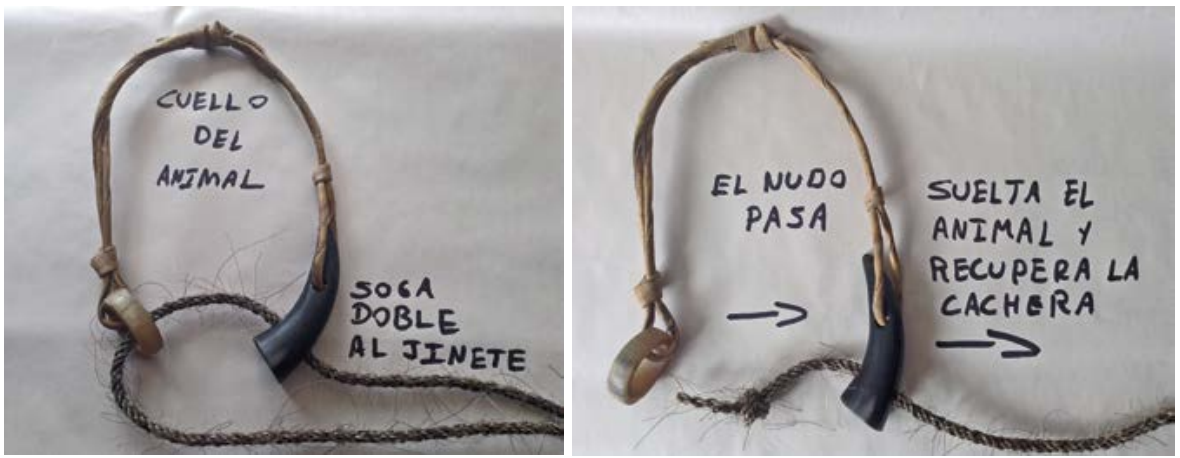

Figura 11. Mecanismo de la cachera

Fuente: archivo personal del autor

Su técnica de uso se puede explicar así: una vez enlazado, el trabajador de llano debe colear el animal para tumbarlo e instalarle la cachera — casi siempre con ayuda de otro vaquero, dependiendo del nivel de experticia-, que va atada a una soga doble de al menos unos 30 o 40 metros de longitud. Este cabo de soga lleva entonces, en una de sus puntas, al toro atado en el cuello por la cachera, y la otra punta va atada, ya sea a la cola del caballo (arrebiatada) o a la cabeza de la silla (arcionada), según el territorio donde se realiza el trabajo o la costumbre del vaquero que realiza la tarea. Uno de esos dobleces lleva un nudo en la punta de la soga que, al soltarlo desde el caballo, traba el paso en la punta de cacho perforado (macho), pero que pasa libre a través de la argolla (hembra) de cacho, y de esta manera libera el animal y se recupera la cachera sin correr riegos, sin tener que tumbar el vacuno nuevamente y sin bajarse siquiera del caballo, cuando el trabajador de llano lo haya conducido (lajiado) hasta el rodeo indicado (figura 11).

Podemos inferir, a partir de la cachera, no solo sus técnicas de uso y necesidad del objeto en el manejo y la doma del ganado, sino también realizar una reconstrucción, a una pequeña esala por tratarse solo de un objeto, de la sociedad que lo construyó, al igual que podríamos hacerlo basados en un canto de trabajo, si entendemos los objetos como "una materialización de lo que los humanos hacen para sobrevivir, no solo en un sentido funcional o pragmático, sino también desde un punto de vista cognitivo, afectivo, simbólico o emotivo" (Sanín, 2016, p. 35). Se pueden inferir también algunos conceptos de la propiedad territorial — sabanas libres y ausencia de propiedad privada - que afectaba el pastoreo de los ganados y hacía necesario el desarrollo de objetos como este. Se puede entender la necesidad de desarrollar destrezas en los llaneros para poder sobrevivir en un mundo como aquel; se puede entender 
también, hasta cierto punto, la distribución del trabajo - el trabajo de llano que requiere de una cachera suele ser para los varones, pero en el ordeño, que se realiza con vacas mansas, es más frecuente la participación de mujeres con los cantos de ordeño-. Se pueden entender también algunas características del territorio, como la ausencia de vías de comunicación y la falta de acceso a tecnologías propias de la urbes, que propiciaron el desarrollo de un objeto como este, en función de su relación con el entorno ecológico, y así ir solventando las dificultades de acceso a estos lugares.

Si hacemos la lectura del mismo objeto en el presente, podemos observar cómo su uso se restringe ahora a unos pocos hatos como El Sinaí o Barley, en zonas como Casanare y Arauca, donde sobrevive su uso en los trabajos de llano como una manera de recordar las prácticas de antaño — una nostalgia — por orden de sus dueños, mas no como una necesidad. Además de realizar prácticas en las que se usan algunos objetos de este orden, también se realizan actividades tradicionales como el jaripeo ${ }^{4}$ de toros y caballos y el coleo huesia'o ${ }^{5}$, pero solamente durante uno o dos de los diez o quince días que puede durar el trabajo de llano.

Lo concreto es que en la mayor parte del territorio un objeto como la cachera hoy día sobrevive formando parte de los objetos ornamentales de las salas de las viviendas en poblaciones llaneras, y son valorados por su carga simbólica — dimensión comunicativa de los objetos-, que rememora un llano que está experimentando transformaciones aceleradas por diversas razones, pero que ellos - los viejos trabajadores de llano y muchos de sus hijos-logran mantener en su memoria a través de objetos como este. Porque “cada uno de nuestros objetos prácticos está ligado a uno o varios elementos estructurales, pero, por lo demás, todos huyen continuamente de la estructuralidad técnica hacia los significados secundarios, del sistema tecnológico hacia un sistema cultural” (Baudrillard, 1968, p. 6).

4 Se le conoce a esta práctica como el acto de montarse sobre el lomo de un caballo cerrero o de un toro cimarrón, sin silla y sin protección alguna, a plena sabana abierta, con el objeto de soportar la mayor cantidad de tiempo posible sobre su lomo antes de dejarse caer o antes de que el propio animal tumbe al jinete.

5 Este tipo de coleo está casi extinto hoy día, y en cuanto diversión, se realiza en muy pocos lugares de Arauca. Consiste en perseguir una res a alta velocidad, montando un caballo adiestrado para el coleo, hasta que el jinete logre agarrar el rabo del vacuno con una de sus manos; en ese momento, el coleador debe saltar del caballo y mantener la velocidad a la que va la res, para terminar tirando la cola tan fuerte que logre tumbarla sin la ayuda del caballo. La práctica puede apreciarse en la película Séptimo paralelo. 


\section{Los objetos sonoros y materiales, sus correlaciones}

Si pensamos en que "los objetos son la dimensión material de la cultura [...]" y que “[...] a través de ellos, y especialmente en la manera en que son puestos en práctica se hacen visibles las normas, los valores y actitudes de la sociedad" (Roth, citado por Sanín, 2016, p. 23), podemos proponer entonces un acercamiento al universo de los objetos asociados a los cantos de trabajo de llano, a través de un paralelismo entre lo material y lo intangible de esta manifestación. Por qué no pensar un canto de ordeño como un objeto sonoro, si el análisis que se hace a un objeto material - la cachera, por ejemplo- puede funcionar para analizar un objeto sonoro, cumpliendo con los mismos atributos desde las categorías de análisis propuestas y obteniendo resultados satisfactorios en cuanto a la dimensión material desde el concepto de objeto sonoro - percepto acústico- de la cultura. El percepto, como concepto propuesto por la psicología cognitiva, es la unidad psicológica básica del conocimiento sensible, aquello que se conserva como unidad de sentido, como bloque de sensaciones (Deleuze y Guattari, 1993). El percepto acústico es todo aquello que puede ser percibido como estímulo acústico y dotado de significados y sentidos.

Así, el objeto sonoro está entendido como un percepto acústico que, una vez percibido, puede ser dotado de valores estéticos, funcionales o simbólicos; para el caso sería cualquier sonido específico al que se le atribuye un fin. Por ejemplo, el japeo, que consiste en un sonido repetitivo que se usa para el arreo, o el simple grito, que en un momento dado del arreo o del acto de atajar una res que huye, cumple una función primordial de llamar la atención del animal y evitar su huida. Estos sonidos están incluidos en la caracterización realizada de los cantos de trabajo de llano, según el PESCU. Y también entendidos como objetos sonoros, hablamos de los cantos de ordeño, cantos de vela y cantos y lecos de cabrestero. Por tanto, en este caso específico, se los puede reconocer como objetos sonoros asociados al trabajo de llano o como cantos de trabajo de llano.

Siguiendo esta línea de reflexión, se puede afirmar entonces que un canto de ordeño en cuanto objeto sonoro, desde la perspectiva teórica de Sanín (2016), posee dimensiones funcionales, estructurales y comunicativas. En el marco de lo funcional podemos decir que los portadores usan el canto de ordeño para relajar las vacas y dinamizar las relaciones y formas de comunicación entre los participantes de la tarea del ordeño. En cuanto a la dimensión estructural, al igual que con la cachera, podemos analizar los materiales con que se construye el objeto, y en este caso particular rastrear la procedencia de dichos materiales, determinando sus momentos y 
lugares. Por ejemplo, los portadores han declarado que el elemento que estructura el canto de ordeño está constituido por el nombre de la vaca, que usualmente hace referencia a su color de pelo (ejemplo: Pan Quemao o Nube de Agua), a través del cual se usan algunos rasgos melódicos transmitidos previamente a través de la experiencia y la transmisión intergeneracional, y que son transformados en el momento de la interpretación - momento del ordeño-, siguiendo la rima y el ritmo impuestos por el nombre de la vaca — una palabra o grupo de palabras (el nombre) constituyen el elemento estructurante para la improvisación del canto-.

Por último, el aspecto comunicativo del canto de ordeño dota de sentido la tarea misma del ordeño, tanto en las relaciones entre ordeñadores, becerreros y camaseadores $^{6}$, como también en la relación hombre-animal. Si la vaca no se deja ordeñar, patea, se mueve o se muestra incómoda, el ordeñador debe acariciarla mientras le canta su nombre, pidiéndole calma y disposición para el ordeño. Con base en los ejemplos tomados, de la misma forma como analizamos y comprendemos la cachera en su materialidad, podemos también hacerlo con un canto de ordeño en su inmaterialidad, porque forma parte de un mismo universo articulado.

Desde otra perspectiva, también "la cultura y los objetos están estrechamente relacionados y una de las maneras en las que las categorías culturales pueden ser comprobadas, es a través de los objetos materiales de una cultura" (Howes, citado en Sanín, 2016, p. 23). Esto también puede ser comprobado si se piensa en los cantos de trabajo de llano como objetos sonoros a través de los cuales se pueden realizar comprobaciones de gran parte de las categorías de la cultura llanera.

Si se pretende ser consecuente con la gestión institucional desde la inclusión en la LRPCI y propender a la salvaguardia de los cantos, esta manifestación debe ser reconocida, apropiada y transmitida en todos los espacios participativos y comunitarios donde se puedan empezar a resignificar y revitalizar. Pero se debe fortalecer la mirada institucional del PEScu, incluyendo el universo material e intangible, comprendiendo los cantos como una unidad llena de sentidos y significados que puede ser transmitida y valorada por otras sociedades, no solo a través de concursos y tarimas de festivales para los cantos o de escuelas de artesanía y museos para los objetos, de forma independiente o desarticulada. Este problema común existe aún en

6 Estos participantes del ordeño son usualmente aprendices o niños que tienen estas tareas encargadas: el becerrero arrea los becerros hasta donde se encuentra el ordeñador con la vaca y el camaseador sostiene la camaza — cuando no hay burro- debajo de la ubre de la vaca, mientras el ordeñador hace su trabajo. Algunas veces una misma persona es becerrero y camaseador. 
[...] los países en que la legislación y los discursos oficiales adoptan la noción antropológica de la cultura, que confiere legitimidad a todas las formas de organizar y simbolizar la vida social, pero que mantiene una jerarquía de los capitales culturales: vale más el arte que las artesanías, la medicina científica que la popular, la cultura escrita que la oral. (García-Canclini, 1999, p. 17)

Este hecho se ha manifestado mostrando una sonrisa de políticas culturales incluyentes, multiétnicas y diversas en el discurso, pero adoptando, en la realidad de la práctica, cierta tímida jerarquía colonial, y abriendo espacios participativos que, en una lectura profunda, están dando a entender un arraigado miedo a la ruptura de esa mirada colonialista. Dicha mirada se alimenta y se mantiene a través de las instituciones por medio del poder y el control sobre los elementos de la cultura, para ordenarlos, describirlos y catalogarlos, en un complejo proceso que a su vez genera contradicciones y tensiones entre portadores, instituciones, comunidades y gestores, pero que pareciera que debemos aceptar como algo necesario para mitigar las amenazas de desaparición de algunas manifestaciones culturales en riesgo.

Tras cinco años de haber patrimonializado los cantos, empiezan a abundar espacios de circulación en los festivales de música llanera de los cuatro departamentos de la Orinoquia. Las secretarías de turismo y cultura y los alcaldes municipales pregonan el "rescate" de esta manifestación y su tradición, auspiciando concursos de canto de ordeño y lecos de cabrestero. Pero, ¿por qué se ha elegido de manera generalizada el concurso como estrategia de circulación y "salvaguardia”?, ¿cuál es el criterio?, ¿quiénes son los interesados en auspiciar estas prácticas?

Primero cabe notar si esta realidad corresponde a una decisión informada y documentada, y segundo, si la homogeneización y normalización de esta estrategia - el concurso - ha tenido que ver con un trabajo juicioso de consulta a los depositarios o portadores de la manifestación y a las comunidades participantes y receptoras. Hay al menos dos grandes razones para comprender por qué ocurre: la primera, el territorio de los cantos es excesivamente grande para los recursos destinados por los aparatos del Estado, y, por tanto, la implementación del PEScu no ha sido suficiente, pues requiere de una gran cantidad de tiempo y de capital social y económico, así como de estrategias bien diseñadas para cada contexto; por eso los funcionarios locales optan por la estrategia potente de divulgación y mercado que desde hace décadas tienen el joropo y los festivales de música llanera; la segunda, la dispersión de los portadores y gestores en un territorio extenso sin medios de comunicación efectivos, que no ha permitido congregar y articular un grupo gestor o una red de salvaguardia que permita unas acciones más acordes con las necesidades de la manifestación. 
De otro lado, es importante una reflexión sobre la manera en que se está entendiendo, y sobre todo comprendiendo, el patrimonio cultural en los contextos locales de los cantos. ¿Podría ser que se está asumiendo como una nueva forma de producción cultural en el presente, que tiene como recurso el pasado, manifestándose en la práctica, por tanto, como un valor agregado de la industria cultural, como un espectáculo diferente o novedoso para la tarima? Esta es la idea que expone Kirshenblatt-Gimblett (1995) y se evidencia al observar lo que está sucediendo. Quizás un planteamiento de valoración y salvaguardia articulado con su universo material desde un comienzo no hubiera llevado al aprovechamiento facilista de los circuitos del joropo que ha dado como resultado el fortalecimiento de una estrategia de salvaguardia basada casi exclusivamente en la divulgación de un producto sonoro. Esto habría demandado nuevos retos a ese gigantesco aparato de mercado que representa la música llanera en la Orinoquia, y que es el ente que se ha apoderado de la salvaguardia de los cantos en gran parte del territorio, amparado por las instituciones locales.

Este modelo de gestión local de los cantos se manifiesta también como una herramienta más de control político, arraigada en discursos de identidad esencialista y nacionalismos, que redundan en los fáciles réditos políticos demostrables a través de cifras e indicadores antes expuestos. Todo esto en cierta medida está pasando: el patrimonio en este contexto está siendo convertido en exhibición, en erotización, en espectacularización del pasado, para dotarlo de un nuevo ropaje, evitando así su muerte a través del espectáculo, para que Eros se yerga victorioso sobre Tánatos. De ser así, ¿podríamos decir entonces con tranquilidad que "el patrimonio es creado a través de un proceso de exhibición (como conocimiento, como performance o como exhibición de museo), y así esta exhibición dota al patrimonio de una segunda vida”? (Kirshenblatt-Gimblett, 1995, p. 369).

Luego de su inclusión en la LRPCI, las miradas hacia los cantos, especialmente las que provienen de las instituciones encargadas de gestionar el patrimonio cultural a escala municipal y departamental, se han venido centrando en su aspecto musical, estético y, principalmente, en su importancia como producto cultural de masas para la atracción turística: los cantos de ordeño brillan por sus melodiosas líneas vocales y sus evocadores textos; los lecos de cabrestero impresionan por su derroche de energía y por el fulgor de la demanda técnica por parte del ejecutante, que ya son tema de estudio vocal también en las academias municipales de música; los cantos de vela hablan de una época que se fue para no volver, porque ya no se realizan travesías con 
ganado de cuarenta días con sus noches; y los gritos, silbos y japeos hablan de una extraña forma de comunicación entre hombres y animales, que en algunos rincones de la sabana aún se niega a morir.

Esta nueva cara de los cantos ha llegado para quedarse en las tarimas de todos los escenarios como un producto musical más al lado del joropo y sus innumerables concursos y festivales de interpretación para ejecutantes que compiten, en muchos casos, desconociendo los contextos de esta práctica y su valor como patrimonio cultural. Se objetivan desde afuera del entorno en que se originaron y son fomentados por el interés contemporáneo hacia "ciertas formas culturales tradicionales que tienen el efecto paradójico de transformarlas en una especie de representación de cara a lejanos públicos receptores, privilegiando sus dimensiones externas sobre los sentidos que los actores les puedan dar" (Cruces, 1998, p. 83).

Cuando nos acercamos por primera vez al mundo material de los "cantos de trabajo de llano" y a sus depositarios, desde las charlas, la experiencia en terreno y la relación con sus contextos, empezamos a entender la interrelación existente entre los objetos asociados, lo intangible, lo simbólico y lo ritual. Cantarle al ganado para un portador de estos cantos es una demanda — de la tradición, de los ancestros, de la cultura-y una necesidad que, para él o ella, no se pone en duda. Ese canto es un objeto sonoro que al igual que uno material, como la cachera, simboliza la memoria de su territorio, su tradición familiar y sus procesos de construcción identitaria. Llega a tener atributos de ritualidad similares a una cifra de velorio, a un rosario de angelitos o a una zafra de muerto en el Caribe, que se evidencian cuando se deben llevar a un escenario, en un festival, donde se interpretan fuera de su contexto y el cantador lo pone de manifiesto improvisando una camaza, un burro, imaginando una ubre, una vaca, tratando de reconstruir todo un contexto para representar todo lo que de ritual cotidiano tiene la experiencia diaria del ordeño, en la relación íntima con los animales.

De manera similar, obviando la religiosidad individual y la fe, se puede entender esta interrelación desde cierto paralelismo con los objetos de carácter religioso, adoptando la idea de que todo mundo religioso o simbólico está construido alrededor de objetos con distintos valores y significados para los prosélitos. Además, “[...] este paradigma no es exclusivo de lo religioso, ya que cualquier objeto, imagen o representación puede tener un fuerte simbolismo, capaz de establecer, perpetuar o destruir relaciones entre individuos y otros (vivos, muertos, deidades, espíritus, etc.)” (Agulló Hernández, 2010, p. 2). 


\section{Conclusiones}

Finalmente, y en pro de entender mejor la integralidad de este universo cultural, "los lugares se configuran como contextos a partir de los objetos que pueblan un espacio, y a partir de los cuales es posible establecer diferencias de cualquier tipo" (Sanín, 2016, p. 23). Es decir, sabemos que constituimos un contexto denominado “corral de ordeño", no solo porque hay objetos materiales como la cerca o empalizada que lo limita, los llaveros y trancas que sirven para abrir y cerrar el corral, los botalones para achicar las vacas de ordeño, el sujeto para tenerlas quietas mientras se ordeñan, el burro y la camaza para ordeñar, sino también porque dentro de este hay objetos sonoros representados en silbos, japeos, cantos de becerrero y cantos de ordeñador. Estos objetos - materiales y sonoros - le permiten a un observador determinar que está en un contexto de corral de ordeño y no en uno de arreo en sabana abierta, o en uno de paradero o de salero, que exigirían la presencia de otros objetos y de otros cantos o sonidos. ¿Se podría entonces hablar de algún tipo de antropología y, si realmente se quiere, también de salvaguardia a partir de los objetos desde su integralidad (material e intangible), para esta manifestación, como una opción que pueda ser más incluyente? Por ahora esta integralidad es una propuesta que va quedando como producto de este trabajo reflexivo, y que nos va quedando como tarea para un desarrollo posterior.

A partir de la valoración del universo material y la relación dinámica que se logra establecer con lo intangible de los cantos, se pueden abrir formas de revitalización, refuncionalización y resignificación para esta manifestación, ante los acelerados cambios que experimenta su territorio. Es usual que los vínculos simbólicos que se dan entre los objetos y las personas desde la cotidianidad suelan darse de manera inconsciente. Por tanto, para traerlos al plano de la conciencia, se requiere de procesos reflexivos que no son comunes en la relación sujeto-objeto de una comunidad como la depositaria de los cantos. Es necesario, por tal motivo, en un ámbito de pedagogía para el patrimonio cultural, propiciar espacios reflexivos entre las comunidades participantes, el público receptor y las comunidades de portadores, para definir estrategias de salvaguardia consensuadas que tengan en cuenta las particularidades de cada territorio - el territorio de los cantos es extenso y diverso-. Solo después de un proceso como este, o de algún otro que propicie estos espacios de reflexión, se puede determinar una estrategia de salvaguardia tendente a ser integral entre lo material y lo inmaterial y que permita una real participación de los actores, porque así como "ningún objeto, en un museo, suele decir su mundo” (Lull, 2007, p. 14), 
tampoco un canto de arreo o de ordeño, suelto, desatado de su contexto y lanzado desde una tarima ante una multitud, puede hablar del mundo que lo subyace.

Así como vamos a un museo arqueológico, "atraídos por el interés de contemplar objetos que nos son desconocidos y descubrir sus misterios, o ver en ellos algo que perdimos, que nos constituya y que nos sea propio” (Lull, 2007, p. 13), también podemos, por medio de los objetos asociados al trabajo de llano y sus cantos, aproximarnos a la historia, la identidad y la substancia de lo que hacemos como investigadores, portadores y, ojalá, como encargados de la gestión del patrimonio a escala institucional.

Para propender, desde la mirada patrimonial, hacia la existencia de una gestión social de estas manifestaciones,

[...] no basta con que el tema sea tradicional, oral o popular; es mucho más importante que la perspectiva de los protagonistas esté incorporada en él, que puedan reconocerse a través suya [sic]. Mediante estrategias interactivas en la elaboración y presentación de los materiales los potenciales receptores participan directa o indirectamente en la conformación del resultado final. (Cruces, 1998, p. 84)

Para esto, se deben implementar estrategias de salvaguardia que tengan en cuenta las múltiples prácticas, objetos, saberes, usos y costumbres que conforman el entramado cultural sobre el que reposan los cantos.

Muchas veces se ha dicho que uno de los valores más fuertes del patrimonio cultural es que conforma la identidad de un grupo social en cuyo seno este nace, se transmite y se transforma. Entonces debemos también preguntarnos, en el caso de los cantos de trabajo de llano, si la cuestión "no es cómo una determinada obra musical o una interpretación refleja a la gente, sino cómo la produce, cómo crea y construye una experiencia” (Frith, 2011, p. 184). Para esto, no debemos olvidar que este es un patrimonio vivo y dinámico, que así como este se construye también construye identidades e imaginarios y transforma de diversas maneras su contexto.

Por tanto, más aún debemos preguntarnos de qué manera estas mismas manifestaciones, estos cantos, sus prácticas y saberes asociados, en algún momento de nuestro presente o de nuestro futuro, pueden llegar a transformar a las personas o los grupos sociales que las produjeron en algún punto de su historia, y aceptar más bien que "la pregunta que deberíamos hacernos no es qué revela la música popular sobre 'la gente', sino cómo la construye” (Frith, 1987, p. 137), y así poder, quizás, empezar a comprender verdaderamente nuestro patrimonio cultural, a convivir con él de forma participativa, de una manera más integral, menos esencialista y menos fragmentada. 


\section{Sobre el autor}

Jhon Emerson Moreno Riaño. Músico egresado de la Universidad de los Andes, candidato a magíster en Patrimonio Cultural de la Universidad Pedagógica y Tecnológica de Colombia (UPTC), Tunja, Boyacá, y miembro del Grupo Interdisciplinario de Investigaciones Arqueológicas e Históricas de esta misma universidad. Es investigador en el área de patrimonio cultural, ganador de la beca de investigación otorgada por los "Fondos concursables para la salvaguardia del patrimonio cultural inmaterial de América Latina del Crespial, 2017”. Obtuvo reconocimiento por el Ministerio de Cultura en la convocatoria Distintas maneras de narrar el patrimonio cultural colombiano, en 2018. Es autor de los libros Casos y cachos llaneros y La sombra que pasa, ganadores de los premios Beca para Publicación de Libro Inédito de Interés Regional y Beca para la Publicación de Obra Inédita, ambos de 2019, del Ministerio de Cultura.

\section{Referencias}

Agulló Hernández, D. (2010). La mirada antropológica de los objetos. Periféria, 13(2), 61-66.

Arias Vanegas, J. (2004). Ganadería, paisaje, territorio y región. Una historia ecológica y social de la Orinoquia colombiana. Bogotá: Instituto de Investigación de Recursos Biológicos Alexander von Humboldt.

Baudrillard, J. (1968). Le système des objets. París: Gallimard.

Bortolotto, C. (2014). La problemática del patrimonio cultural inmaterial. Culturas: Revista de Gestión Cultural, 1(1), 1-22. Recuperado de https://polipapers.upv.es/index.php/cs/ article/view/3162/3610

Caicedo Terán, S. L. y Espinel, O. (2018). Educación indígena Kamëntzá. Crianza, pensamiento, escucha. Praxis \& Saber, 9(20), 15-40.

Cruces, F. (1998). Problemas en torno a la restitución del patrimonio. Una visión desde la antropología. Alteridades, 8(16), 75-84.

Deleuze, G. y Guattari, F. (1993). ¿Qué es la filosofía? Barcelona: Anagrama.

Frith, S. (1987). Towards an aesthetic of popular music. En R. Leppert y S. McClary (Eds.), Music and society: the politics of composition, performance and reception (pp. 133-150). Cambridge: Cambridge University Press.

Frith, S. (2011). Música e identidad. En S. Hall y P. du Gay (Eds.), Cuestiones de identidad (pp. 181-213). Buenos Aires-Madrid: Amorrortu.

García-Canclini, N. (1999). Los usos sociales del patrimonio cultural. En E. A. Criado, Patrimonio etnológico: nuevas perspectivas de estudio (pp. 16-33). Andalucía: Junta de AndalucíaConsejería de Cultura-Instituto Andaluz del Patrimonio Histórico-Editorial Comares. 
Gupta, A. y Ferguson, J. (2008). Más allá de la "cultura”: espacio, identidad y las políticas de la diferencia. Antípoda, (7), 233-256.

Kirshenblatt-Gimblett, B. (1995). Theorizing heritage. Ethnomusicology, 39(3), 367-380.

Lacarrieu, M. (2008). ¿Es necesario gestionar el patrimonio inmaterial? Notas y reflexiones para repensar las estrategias políticas y de gestión. Boletín Gestión Cultural, (17), 2-26. Recuperado de http://www.gestioncultural.org/boletin/2008/bgc17-MLacarrieu.pdf

Lull, V. (2007). Ética y arqueología. En Trabajos de prehistoria (pp. 13-21). Barcelona: Museo de Arqueología de Cataluña.

Ministerio de Cultura. (2013). Cantos de trabajo de llano. Recuperado de http://www.mincultura.gov.co/prensa/noticias/Documents/Patrimonio/15-Cantos\%20de\%20trabajo\%20 de\%2OLlano\%20-\%20PES.pdf

Ministerio de Cultura. (2014). Resolución 054 de 2014. Por la cual se incluye la manifestación Cantos de Trabajo en la Lista representativa del patrimonio cultural inmaterial y se aprueba su Plan Especial de Salvaguardia de carácter urgente. Recuperado de https://www.mincultura.gov.co/prensa/noticias/Documents/Patrimonio/15-Resolucion\%20Cantos\%20 de\%20Trabajo\%20de\%20LLano.pdf

Noguera, J. F. (2002). La conservación del patrimonio arquitectónico. Debates heredados del siglo xx. Ars Longa, (11), 107-123.

Pérez Radziunas, A. (2014). El territorio de los cantos de trabajo de llano: espacialización de una manifestación inmaterial (tesis de maestría), Pontificia Universidad Javeriana, Bogotá. Recuperada de https://repository.javeriana.edu.co/bitstream/handle/ 10554/15560/PerezRadziunasAndreaDanute2014.pdf;jsessionid=4AC238E66EBCE19 $495402003179025 \mathrm{FB}$ ? sequence $=1$

Pinzón Martínez, E. (1991). Historia de la ganadería bovina colombiana. Vol. 4, n. ${ }^{0}$ 1, suplemento ganadero. Bogotá: Banco Ganadero.

Rausch, J. (1994). Una frontera de la sabana tropical, los llanos de Colombia 1531-1831. Bogotá: Banco de la República.

Reyes, F. (2003). Eso sí es llano cuñao. Etnografía de un hato llanero en Casanare. Bogotá: Universidad de los Andes. Recuperado de https://repositorio.uniandes.edu.co/bitstream/ handle/1992/15881/u239771.pdf?sequence=1

Romero, M. E. y Romero, C. (1989). Desde el Orinoco hacia el siglo xxi: el hombre, la fauna y su medio. Bogotá: Fondo FEN Colombia.

Salge Ferro, M. (2018). El principio arcóntico del patrimonio. Bogotá: Ediciones Uniandes.

Sanín, J. D. (2016). Estéticas del consumo: configuraciones de la cultura material. Medellín: Universidad Nacional de Colombia. Recuperado de http://cmap.upb.edu.co: http://cmap. upb.edu.co/rid=1153175739921_1060940786_1049/EST\%C6\%92TICAS\%20DEL\%20 CONSUMO.\%2OJuan\%20Diego\%20San\%E2\%80\%99n\%20Santamar\%E2\%80\%99a.pdf 
Santamarina Campos, B. (2013). Los mapas geopolíticos de la Unesco: entre la distinción y la diferencia están las asimetrías. El éxito (exótico) del patrimonio inmaterial. Revista de Antropología Social, 22, 263-286.

Unesco. (2017). Cantos de trabajo de los Llanos de Colombiay Venezuela. Recuperado de https://ich. unesco.org/es/USL/cantos-de-trabajo-de-los-llanos-de-colombia-y-venezuela-01285 